evidence of this absence of symmetry, I have adduced the fact that camphor gives unequal yields of borneol and isoborneol on reduction, proving that the two links of the double bond are of unequal strength. It is, therefore, a mere unjustified analogy which has led to the assumption that the carbonyl-group of camphor is a symmetrical radical, and no further evidence is required to justify the view that the carbon atom of the ketonic group is in fact an asymmetric carbon atom, i.e. that it possesses an induced asymmetry, in view of the influence upon it of the fixed asymmetry of two of the saturated quadrivalent carbon atoms. This property of induced asymmetry appears to be very frequent in unsaturated optically-active compounds, and can be used in order to account for the presence of low-frequency partial rotations in many compounds in which the unsaturated group is not too far removed from the fixed asymmetric centres.

In this address I have presented an intimate mixture of Biot's researches with those of my colleagues of the present day. The fact that so intimate a blend is possible is in itself a tribute to the genius of Biot, whose work, although carried out with the mechanical equipment of the nineteenth century, was always conceived in the spirit of the twentieth century.

\title{
The American Bison: A Questionable Experiment.
}

\author{
By Dr. James Ritchie.
}

TH TIRTY-EIGHT years ago the sum total of American bison had been reduced from the millions of a century earlier to a number estimated by Hornaday at rogr, and there was a prospect that the species might become extinct. The situation was saved by the action of the Governments of the United States and of Canada, each of which placed remnants of the dwindling herds under protection in large reserved areas. The rapidity with which the protected animals recuperated is well illustrated by the history of the Canadian herd. In 1907 the Dominion Government, acting through the Department of the Interior, purchased the 709 members of the herd owned by Michael Pablo of Montana, which can be traced back to 4 wild calves captured by an Indian in 1873 . By 1909 the Pablo herd had been set at large in the Buffalo National Park at Wainwright, an area I 5 miles long and ${ }_{3} 3$ miles wide, and in 1925 this herd was found to number approximately 12,000 head, the increase in sixteen years being about 11,300 . The future of the species in Canada, therefore, seems to be assured. So far, the success of the experiment of protection has been all that could be desired.

A new difficulty now faced the authorities in Canada. The area of close on 200 square miles set aside for the original herd was insufficient to support the new numbers, and some method of reducing the numbers and of disposing of the annual increase had to be devised. Some 2000 have been slaughtered for food and robes, some have been transferred to other parks, including a pair sent to the Scottish Zoological Park in Edinburgh, and more than 1600 have been transported northward for 700 miles to Wood Buffalo Park in the North-West Territories. The Wainwright stock now reduced to about 8000 , or about one to I6 acres, must be still near the food limit of the area (Io acres to one sheep is a rough guide to the food capacity of Scottish mountain pastures), but arrangements are being made for the disposal of the annual increase, which in the full herd amounted to I 500 individuals a year. It is, however, to the transference of large numbers to Wood Buffalo Park that attention is here particularly directed.

The Department of the Interior is to be congratulated on the success of the work of transference; for, by means of specially designed cars and barges, I634 bison were moved by rail and water for 700 miles with only 8 casualties. But the transference gives rise to some doubt from the scientific point of view.

In Wood Buffalo Park there existed the only herd of wild bison which has survived, and these, the "wood buffalo," have been separated from the "plains buffalo" of the reserves as a distinct race, Bison bison athabasce, characterised by its larger size, darker colour, more dense and silky hair, and larger and more incurved horns. Whether these characters are due to innate variation emphasised by segregation, or are simply the evidences of the effect of a different environment, is not known. At any rate, this race has now little likelihood of survival as a pure strain, for amongst its members, which probably do not exceed $\mathrm{I} 500$ in number, have been deposited I600 individuals of the contradistinctive race of the plains; and the wardens report that "the plains and the wood buffalo are mingling freely and that there is every prospect of the complete amalgamation of the two herds."

From the scientific point of view the opportunity of making an interesting experiment has been missed. Had the surplus plains buffaloes been deposited in an area similar in latitude, vegetation and climate to Wood Buffalo Park, but isolated from it, instead of in the Park itself, the wood buffalo race would have remained uncontaminated, and time would have shown whether in the new environment the plains buffalo would have assumed the distinctive characters of the wood buffalo. Had it turned out that these characters were wholly environmental, as they may well be, an interesting biological correlation would have been proved, and no objection could then have been taken to fortifying the wood buffalo herd by the addition of plains individuals.

In the meantime two suggestions may be made. First, in view of the possible swamping and disappearance of the distinctive wood buffalo as the result of crossing, it should be assured that several pure-bred typical specimens of that race find a place in one or more of the Dominion or other great museums. Secondly, if it be possible, the next batch of surplus plains buffaloes to be transferred from Wainwright should be placed in a northern area other than Wood Buffalo Park, with the view of establishing a new and independent herd in which the influence of climate might be watched. The result would finally condemn or vindicate the 1925 experiment of commingling the two racial forms. 